Journal of Non-Crystalline Solids 359 (2013) 9-14

http://dx.doi.org/10.1016/j.jnoncrysol.2012.09.025

\title{
Synthesis and characterization of spherical amorphous alumo-silicate nanoparticles using RF thermal plasma method
}

\author{
Audrone Jankeviciute ${ }^{\mathrm{a},}$, Zoltán Károly ${ }^{\mathrm{b}}$, Nadezda V. Tarakina ${ }^{\mathrm{c}}$, János Szépvölgyi ${ }^{\mathrm{b}}$, Aivaras Kareiva ${ }^{\mathrm{a}}$ \\ a Department of General and Inorganic Chemistry, Vilnius University, LT-03225 Vilnius, Lithuania \\ b Chemical Research Center, Hungarian Academy of Sciences, H-1025 Budapest, Hungary \\ c Experimentelle Physik III, Physikalisches Institut and Wilhelm Conrad Röntgen—Research Centre for Complex Material Systems, \\ Universität Würzburg, Am Hubland, D-97074 Würzburg, Germany
}

\begin{abstract}
The RF thermal plasma synthesis route was used for the preparation of alumo-silicate spherical particles. Homogeneous solid mixtures of raw materials $\left(\mathrm{Al}_{2} \mathrm{O}_{3}, \mathrm{SiO}_{2}\right.$ and $\left.\mathrm{KOH}\right)$ were used as precursors. $\mathrm{SiO}_{2}$ powders with different particle sizes $(6 \mu \mathrm{m}$ and $40 \mu \mathrm{m})$ were taken for this synthesis. For the characterization of obtained materials, scanning electron microscopy (SEM), transmission electron microscopy (TEM), X-ray powder diffraction (XRD) analysis, infrared spectroscopy (FTIR) and thermogravimetric analysis (TG/DTA) were used. Nanosized amorphous ceramic particles were formed via two-step RF thermal plasma processing. It was demonstrated that the size of the $\mathrm{SiO}_{2}$ particles plays a significant role in the formation of the alumo-silicate nanoparticles.
\end{abstract}

\section{Introduction}

The processing of ternary metal-oxide systems with spherical particles can lead to many desirable applications. Spheres with core-shell structure might be applied more specifically. Nanoscaled core-shell particles are often attractive due to their excellent mechanical properties. In recent years, radio frequency (RF) induction thermal plasma technology has emerged as a novel technique for the manufacturing of modern and enhanced materials, such as preparation of various kinds of nanoparticles in metallic and ceramic systems. This enabling technique adds value to conventional materials. It makes high-quality and highperformance materials and material processing techniques possible [1,2]. Moreover, the recent publications clearly showed that this synthesis method could be easily scaled up [3-5]. Plasma, considered the fourth state of matter, consists of a mixture of electrons, ions and neutral species, but is electrically neutral. "Hot" or "equilibrium" plasmas can be characterised by the approximate equality between heavy particle and electron temperature. Such plasmas are known as thermal plasmas [6]. Arc discharge, which is also often called thermal plasma, has proven to be of beneficial use in the synthesis and surface modification of a broad range of metals and inorganic materials. Its basic advantages can be summarised as follows. Firstly, thermal plasmas have high temperatures (up to b15,000 K). Because the plasmas are generated at relatively high pressures (close to atmospheric pressure), they have high densities and are considered to be at local thermal equilibrium (LTE). That is, the temperatures of heavy particles (such as atoms, molecules and ions) are almost equal to those of light species (electrons). Other advantages are rapid quenching (from $\sim 10^{5}$ to $\sim 10^{6} \mathrm{~K} / \mathrm{s}$ ), high enthalpy of reaction kinetics and high chemical reactivity:high concentrations of chemically reactive radicals enhance the reactivity of thermal plasmas. Large volumewith lowvelocity, oxidation and reduction atmospheres are able aswell [7].Microsized or nanosized spherical powders, depending on the morphology of the starting compounds [8], with narrow particle size distribution, can be formed using thermal plasma processing [9]. Thermal plasma treatment also allows the transformation of irregularly shaped ceramic particles into spherical 
ones. These powders are more likely to be amorphous with small fractions of crystalline material.

The synthesis of fine spherical particles is required for the production of high quality materials [10]. Recently, the design of composite particles has attracted the attention of researchers due to the strong application potential of such particles in a variety of application areas [11]. The rapidly growing interest in nano- and submicrometer-sized composites is driven by new applications including photocatalysts, white pigments, electronic devices, cosmetics, and fillers [12-14]. Powders containing spherical silica are employed in a broad range of applications (electrical, magnetic and structural), and particularly in the processing of plastics (production of nanocomposites) and in adsorptive processes and catalysis $[15,16]$. Glass-ceramic materials consisting of silica or alumina, which can be used in biomedical purposes, for orthopaedic surgery and implantation, are extremely desirable [17-20].

The main aim of this work was to synthesise and characterise spherical alumina-silicate nanoceramics using the RF thermal plasma technique and to investigate the influence of the $\mathrm{SiO} 2$ particle size on the microstructural features of the final products.

\section{Experimental}

For the preparation of precursors, two differently sized crystalline silicon dioxide $\left(\mathrm{SiO}_{2}\right)$ powders $(\sim 6 \mu \mathrm{m}$ and $\sim 40 \mu \mathrm{m})$ were used. Aluminium oxide $\left(\mathrm{Al}_{2} \mathrm{O}_{3}\right)(\sim 10 \mu \mathrm{m})$ and potassium hydroxide $(\mathrm{KOH})$ were source of aluminium and potassium, respectively. The molar ratio of silica/alumina was 4 and the potassium/alumina ratio was equal to 1 . To form a ternary system of $\mathrm{K}-\mathrm{Al}-\mathrm{Si}-\mathrm{O}$, the initial compounds were grinded in an agate mortar until a homogeneous mixture was obtained and placed under an IR lamp for about $1 \mathrm{~h}$ to get rid of the adsorbed moisture from the air. The obtained precursor mixtures were placed in to a sample feeder. The synthesis experiments were carried out in an apparatus consisting of an RF inductively coupled plasma torch (TEKNA PL 35) connected to a reactor (3-5 MHz, max $35 \mathrm{~kW}$ plate power), a cyclone, a filter unit and a vacuumpump. For the plasma torch, differentmixtures of $\mathrm{Ar}$ and $\mathrm{He}$ as central and sheath gases were used. He was chosen as the carrier gas because of its high thermal conductivity and enthalpy, compared to other inert gases [21]. As several attempts showed, the plasma gases and their debit are very important for the successful synthesis of ceramic materials and should be optimised. The parameters of experiments are listed in the Table 1.

Both samples were injected into the hottest spot of the plasma flame. After reaction, the cooled particles were collected from the cylindrical steal reactor. The resulting materials prepared from $\mathrm{SiO}_{2}$ powders with particle sizes of $6 \mu \mathrm{m}$ and $40 \mu \mathrm{m}$ were designated KAS6 and KAS40, respectively.

The PerkinElmer STA 600 instrument was used for simultaneous thermal gravimetry (TG) and differential thermal gravimetry (DTG) analysis. The powder diffraction analysis was performed on a Philips PW 1730 X-ray diffractometer using $\mathrm{CuK} \alpha$ radiation and a signal scanning rate was $10 \mathrm{~min}^{-1}$. The Fourier transform infrared spectroscopy (FTIR) spectra were recorded on a Perkin-Elmer FTIR Spectrum BX II spectrometer. The morphology of the resulting particles was determined with a field emission scanning electron microscope (FESEM), Hitachi SU-70. The transmission electronmicroscopy (TEM) study and energydispersive X-ray (EDAX) microanalysis were performed using a FEI(S)TEM Titan 80-300, operated at $300 \mathrm{kV}$ and equipped with EDAX's Sapphire $\mathrm{Si}(\mathrm{Li})$ Detector. Vendor is EDAX Ltd. For the (TEM) study an ethanol suspension of each sample was prepared and kept in an ultrasonic bath for 5 minutes and then a drop of this suspension was put onto a holey carbon film supported on a $\mathrm{Cu}$ grid. 


\section{Results}

\subsection{Thermal analysis}

Simultaneous TG and DTG analysis was carried out in flowing air atmosphere in alumina crucibles in the temperature range $50-900{ }^{\circ} \mathrm{C}$. Themeasurementsweremade in order to evaluate the possible thermal decomposition processes of the materials obtained during the synthesis. The representative TG/DTG curves of the KAS6 material obtained after RF thermal plasma processing are presented in Fig. 1. Only one weight loss attributed to the liberation of physically adsorbed and bonded water at about $100-400{ }^{\circ} \mathrm{C}$ could be detected on the TG curve. According to the DTG curve the mass loss is peaked at $\sim 170{ }^{\circ} \mathrm{C}$. A total weight loss of about 5\% was determined upon heating for both KAS6 and KAS40 samples. The similar thermal behaviour of both samples is not surprising, since they have no differences in chemical composition. In conclusion, the obtained TG/DTG results allow us to confirm that $\mathrm{RF}$ thermal plasma derived samples are nano-scaled ceramics.

\subsection{X-ray powder diffraction analysis}

The powder X-ray diffraction (XRD) analysis was performed for the qualitative determination of the phase composition of the synthesised products. The XRD patterns of both KAS6 and KAS40 samples were almost identical. A representative XRD pattern of the KAS6 and KAS40 samples is shown in Fig. 2. The XRD pattern displays a very high background and a broad hump at $2 \theta$ around $25^{\circ}$. These features are indications of the amorphous structure of the obtained silicates [22-24]. At the same time we observe that the yield of the solid-state reaction is not $100 \%$, since the diffraction lines are attributable to the raw materials.

Corundum $\left(\mathrm{Al}_{2} \mathrm{O}_{3}\right.$; $\mathrm{PDF}$ [46-1212]) and stishovite $\left(\mathrm{SiO}_{2} ;\right.$ [45-1374]) are present in the same $\mathrm{XRD}$ patterns as well

\subsection{FTIR spectroscopy}

The FTIR spectra were recorded between 4000 and $500 \mathrm{~cm}^{-1}$ (see Fig. 3). FTIR spectra of both samples have similar bands. The intense peak located in the region $1034-1010 \mathrm{~cm}^{-1}$ is attributed to asymmetric and symmetric stretching vibrations of the $\mathrm{Si}-\mathrm{O}-\mathrm{Si}$ groups. The absorption peaks corresponding to the $\mathrm{Al}-\mathrm{O}$ stretching vibrations of $\mathrm{AlO}_{\mathrm{x}}$ polyhedral units are located in the range $850-630 \mathrm{~cm}^{-1}$. The sharp peaks that can be seen in the FTIR spectra at around $1400 \mathrm{~cm}^{-1}$ could be attributed to ionic carbonate $[25,26]$. However, no traces of metal carbonates were determined in the samples by XRD analysis, probably, due to morphous character of carbonates or concentrations are lower detection limit by XRD [27]. Broad bands between 3600 and $3000 \mathrm{~cm}^{-1}$ and absorptions located at $\sim 1640 \mathrm{~cm}^{-1}$ are due to water adsorbed from atmosphere.

\subsection{Electron microscopy}

The morphologies of the resulting KAS6 and KAS40 samples were studied by SEM and TEM. The SEM micrographs of KAS6 and KAS40 samples obtained at different agnifications are shown in Fig. 4. Both KAS6 and KAS40 solids consist of diffused spherical particles. However, it is worth to take a closer look at the microstructure of both samples. Evidently, with increasing particle size of the starting $\mathrm{SiO}_{2}$ powders from 6 to $40 \mu \mathrm{m}$, smaller grains and spherical shape of the synthesis products were achieved. Besides, the specimen KAS40 is less agglomerated, whereas KAS6 particles are strongly connected. Despite both samples being composed of spherical nanoparticles, the surface of the KAS6 sample displays a monolithic microstructure formed by agglomerated particles. On the other hand, the surface of the KAS40 sample is composed of spherical particles that are slightly necked to each other. 
The representative TEM images of the KAS6 and KAS40 samples are shown in Fig. 5. Fine spherical particles are highly agglomerated, and almost, no individual particles can be observed. The contrast of the images is mass-thickness contrast, which should vary smoothly with the diameter of the particles and should change sharply with a change in chemical composition. Since the average $\mathrm{Z}$ number of the core (assumed to be $\mathrm{Al}_{2} \mathrm{O}_{3}$ ) and the shell (assumed to be $\mathrm{K}-\mathrm{Si}-\mathrm{O}$ ceramics) are very close, the latter is not well pronounced. However, for some particles, especially in the case of the KAS40 sample, a sharp change in the contrast is observed, which can be attributed to core/shell structure [28-31] formation. The core and the shell are amorphous as can be seen from both electron diffraction patterns and TEM images (Fig. 6). A high-angle annular dark field STEM image (HAADF-STEM) taken from the same agglomerate of the KAS40 sample is presented in Fig. 6, providing additional evidence of the core-shell structure of the particles. It is unlikely that the contrast appears from the overlapping of particles, even if the particles tend to formagglomerates. EDAX spectra confirm the presence of $\mathrm{Al}, \mathrm{Si}, \mathrm{K}$ and $\mathrm{O}$ in the particles from both studied samples (the spectrum of sample KAS40 is shown in Fig. 7). However, the recorded point and line profile spectra taken along the diameter of some particles do not allow making a solid conclusion about the spatial distribution of these elements. Additional experiments should be performed to reveal the chemical composition of the core and the shell.

Particle size distributions for both samples were evaluated fromTEM images. A total of 150 particles were taken into consideration for each sample. The results of the particle size distribution are presented in histogram form and fitted to a log-normal distribution (see Fig. 8). The average size of the KAS40 particles is found to be $48.00 \pm 26.06 \mathrm{~nm}$, the mode (maximum) of the log-normal distribution is $32.58 \mathrm{~nm}$. The average size of the KAS6 particles is found to be $77.96 \pm 61.43 \mathrm{~nm}$, and the mode (maximum) of the log-normal distribution is $37.71 \mathrm{~nm}$. Thus, the KAS40 sample consists of smaller particles and has a more homogeneous particle size distribution than sample KAS6.

\section{Discussion}

As was mentioned in Introduction, silica and silica containing ceramics having desirable particle size, microstructure and uniform crystallite size distribution have many practical and potential applications [6,32]. Fig. 8 represents particles size distribution and shows that such a size of final particles depends on initials size of $\mathrm{SiO}_{2}$ grains. The bigger $\mathrm{SiO}_{2}$ particles resulted in the smaller $\mathrm{K}-\mathrm{Al}-\mathrm{Si}-\mathrm{O}$ ceramic particles and vice versa. In case when we used $\mathrm{SiO}_{2}$ of $\sim 6$ $\mu \mathrm{m}$ in size, the average size of the final ceramic was $77.96 \mathrm{~nm}$, whereas using $\mathrm{SiO}_{2}$ of $\sim 40 \mu \mathrm{m}$ we obtained powders of $48.00 \mathrm{~nm}$ in size. When we have smaller $\mathrm{SiO}_{2}$ grains, the collision frequency increases and it enhance growth of particles. The X-ray diffractogram (see Fig. 2) showed that thematerialwasamorphous, despite that the initial powders were crystalline. The amorphous characteristic of the obtained powders indicates that the vapours and droplets were efficiently quenched.

The other objective was to evaluate and characterise the morphology of the obtained particles. The molten particles simultaneously get accelerated through the flame and are quenched in the water cooled chamber. During the process the particles get spherical shape due to the surface tension forces. The precursors size reduction of both KAS6 and KAS40 samples witness that they got through instantaneous melting and evaporation in plasma flame. As it can be seen from SEM or TEM pictures (Fig. 4 or Fig. 5) the particles are different in size. We can observe that smaller particles do coalesce with each other and form bigger particles. Two possible ways of the particlescoarsening were proposed [33]. Possibly, the clustering of two or more particles could lead to the formation of $\mathrm{K}-\mathrm{Al}-\mathrm{Si}-\mathrm{O}$ nanoparticles and the clustering of $\mathrm{Al}_{2} \mathrm{O}_{3}$ and $\mathrm{SiO}_{2}-\mathrm{K}_{2} \mathrm{O}$ could lead to the formation of core-shell structures. 
In addition, it was also desired to synthesise nanoparticles with homogeneous compositions. From the EDAX spectra (Fig. 7) we can state that K, Al, Si and O elements are present in the chemical composition of the particles in both KAS6 and KAS40 samples.

\section{Conclusions}

In this study, an amorphous ternary system of alumina-silicate ceramic powders containing an alkaline earth metal was prepared by the RF thermal plasma processing route. For the preparation of precursors, $\mathrm{Al}_{2} \mathrm{O}_{3}(\sim 10 \mu \mathrm{m}), \mathrm{KOH}$ and two differently sized crystalline $\mathrm{SiO}_{2}$ powders $(\sim 6 \mu \mathrm{m}$ and $\sim 40 \mu \mathrm{m})$ were used as starting materials. The TG/DTG results confirm that the RF thermal plasma derived samples were fine-structure $\mathrm{K}-\mathrm{Al}-\mathrm{Si}-\mathrm{O}$ ceramics. The XRD and electron diffraction patterns of the obtained specimens show that they are amorphous. The SEM and TEM measurements revealed that the overall morphology of the synthesised products depends on the initial size of the $\mathrm{SiO}_{2}$ powders used in the RF thermal plasma processing. With increasing particle size of the starting silica, the obtained spherical nanograins of the final powders were smaller and less agglomerated. Moreover, the synthesised alumo-silicate nanoceramics possess a core/shell structure. These nanoscaled core-shell particles could be attractive due to the possibly enhanced mechanical properties for different structural applications.

\section{Acknowledgement}

This research was funded by a grant (No. TAP-LLT-07/2012) from the Research Council of Lithuania. N.V.T. acknowledges funding by the Bavarian Ministry of Sciences, Research and the Arts.

\section{References}

[1] C.P. Yoganand, V. Selvarajan, V. Cannillo, A. Sola, E. Roumeli, O.M. Goudouri, K.M. Paraskevopoulos, M. Rouabhia, Ceram. Int. 36 (2010) 1757-1766.

[2] T. Watanabe, A. Nezu, Y. Abe, Y. Ishii, K. Adachi, Thin Solid Films 435 (2003) 27-32.

[3] M.J. Chen, C.Y. Wu, Y.M. Kuo, H.Y. Chen, C.H. Tsai, Appl. Phys. A Mater. Sci. Process. 108 (2012) 133-141.

[4] P.Y. Lei, A.M. Boies, S. Calder, S.L. Girshick, Plasma Chem. Plasma Process. 32 (2012) 519-531.

[5] J.H. Seo, B.G. Hong, Nucl. Eng. Technol. 44 (2012) 9-20.

[6] I. Mohai, J. Szepvolgyi, Chem. Eng. Process. 44 (2005) 225-229.

[7] T. Ishigaki, J.-G. Li, Sci. Technol. Adv. Mater. 8 (2007) 617-623.

[8] Z. Károly, J. Szépvölgyi, Z. Farkas, Powder Technol. 110 (2000) 169-178.

[9] D. Vollath, J. Nanopart. Res. 10 (2008) 39-57.

[10] Y. Zhu, H.B. Jin, K.G. Ren, S. Agathopoulos, K.X. Chen, Mater. Res. Bull. 44 (2009) $130-133$.

[11] J.M. Kim, S.M. Chang, S. Kim, K.-S. Kim, J. Kim, W.-S. Kim, Ceram. Int. 35 (2009) $1243-1247$.

[12] H. Lei, P. Zhang, Appl. Surf. Sci. 253 (2007) 8754-8761.

[13] J. Szepvolgyi, I. Mohai, Z. Karoly, L. Gal, J. Eur. Ceram. Soc. 28 (2008) 895-899.

[14] Y.F. Tang, Z.P. Huang, L. Feng, Y.F. Chen, Appl. Surf. Sci. 241 (2005) 412-415.

[15] J. Teofil, Mater. Chem. Phys. 113 (2009) 839-849.

[16] X.D. Wang, Z.X. Shen, T. Sang, X.B. Cheng, M.F. Li, L.Y. Chen, Z.S. Wang, J. Colloid Interface Sci. 341 (2010) 23-29.

[17] T.W. Cheng, M.Z. Huang, C.C. Tzeng, K.B. Cheng, T.H. Ueng, Chemosphere 68 (2007) 1937-1945. 
[18] V. Cannillo, F. Pierli, S. Sampath, C. Siligardi, J. Eur. Ceram. Soc. 29 (2009) 611-619.

[19] C.T.Wu, W. Fan, M. Gelinsky, Y. Xiao, P. Simon, R. Schulze, T. Doert, Y.X. Luo, G. Cuniberti, Acta Biomater. 7 (2011) 1797-1806.

[20] I. Bogdanoviciene, A. Jankeviciute, J. Pinkas, A. Beganskiene, A. Kareiva, Mater. Res. Bull. 43 (2008) 2998-3007.

[21] L. Jia, F. Gitzhofer, Plasma Chem. Plasma Process. 29 (2009) 497-513.

[22] C. Özgür, F. Çolak, O. Şan, J. Non-Cryst. Solids 357 (2011) 116-120.

[23] D. Chen, L. Li, J. Liu, S. Qi, F. Tang, X. Ren, W.Wu, J. Ren, L. Zhang, J. Colloid Interface Sci. 308 (2007) 351-355.

[24] Y. Zhang, M. Lv, P.G. Rao, A.Z. Shui, H.Q. Wu, J. Ceram. Soc. Jpn. 115 (2007) 329-332.

[25] N. Dubnikova, E. Garskaite, J. Pinkas, P. Bezdicka, A. Beganskiene, A. Kareiva, J. SolGel Sci. Technol. 55 (2010) 213-219.

[26] A. Jankeviciute, A. Kareiva, Mendeleev Commun. 21 (2011) 287-288.

[27] S.P. Thompson, S.J. Day, J.E. Parker, A. Evans, C.C. Tang, J. Non-Cryst. Solids 358 (2012) 885-892.

[28] D.P. Wang, X. Duan, J.Y. Zhang, A.H. Yao, L.Y. Zhou, W.H. Huang, J. Mater. Sci. 44 (2009) 4020-4025.

[29] R.P. Maiti, S. Basu, S. Bhattacharya, D. Chakravorty, J. Non-Cryst. Solids 355 (2009) 2254-2259.

[30] Y. Sun, G. Guo, B. Yang, X. Zhou, Y. Liu, G. Zhao, J. Non-Cryst. Solids 357 (2011) 1085-1089.

[31] L. Tong, D. Liu, J. Shi, X. Yang, H. Yang, J. Mater. Sci. 47 (2012) 132-137.

[32] W.J. Stark, S.E. Pratsinis, Powder Technol. 126 (2002) 103-108.

[33] S. Samal, D.-W. Park, Chem. Eng. Res. Des. 90 (2012) 548-554. 
Table 1

Parameters of the rf thermal plasma reactor.

\begin{tabular}{|c|c|c|c|c|}
\hline Sample & $\begin{array}{l}\text { Sheath gas } \\
(1 / \mathrm{min})\end{array}$ & $\begin{array}{l}\text { Plasma gas } \\
(1 / \mathrm{min})\end{array}$ & $\begin{array}{l}\text { Carrier gas } \\
(1 / \mathrm{min})\end{array}$ & $\begin{array}{l}\text { Probe position } \\
(\mathrm{mm})\end{array}$ \\
\hline $\mathrm{K}-\mathrm{Al}-\mathrm{Si}-\mathrm{O}^{\mathrm{a}}$ & $\begin{array}{l}\mathrm{Ar}-29.5 \\
\mathrm{He}-18.55\end{array}$ & $\begin{array}{l}\mathrm{Ar}-15.5 \\
\mathrm{He}-7.95\end{array}$ & $\mathrm{He}-5.83$ & $\begin{array}{l}100 \mathrm{~mm} \\
\text { In the middle of the coil }\end{array}$ \\
\hline $\mathrm{K}-\mathrm{Al}-\mathrm{Si}-\mathrm{O}^{\mathrm{b}}$ & $\begin{array}{l}\mathrm{Ar}-26 \\
\mathrm{He}-18.55\end{array}$ & $\begin{array}{l}\mathrm{Ar}-13 \\
\mathrm{He}-2.65\end{array}$ & $\mathrm{He}-5.83$ & $\begin{array}{l}100 \mathrm{~mm} \\
\text { In the middle of the coil }\end{array}$ \\
\hline
\end{tabular}

a Where size of the $\mathrm{SiO}_{2}$ particles is $6 \mathrm{~nm}$.

b Where size of the $\mathrm{SiO}_{2}$ particles is $40 \mathrm{~nm}$.

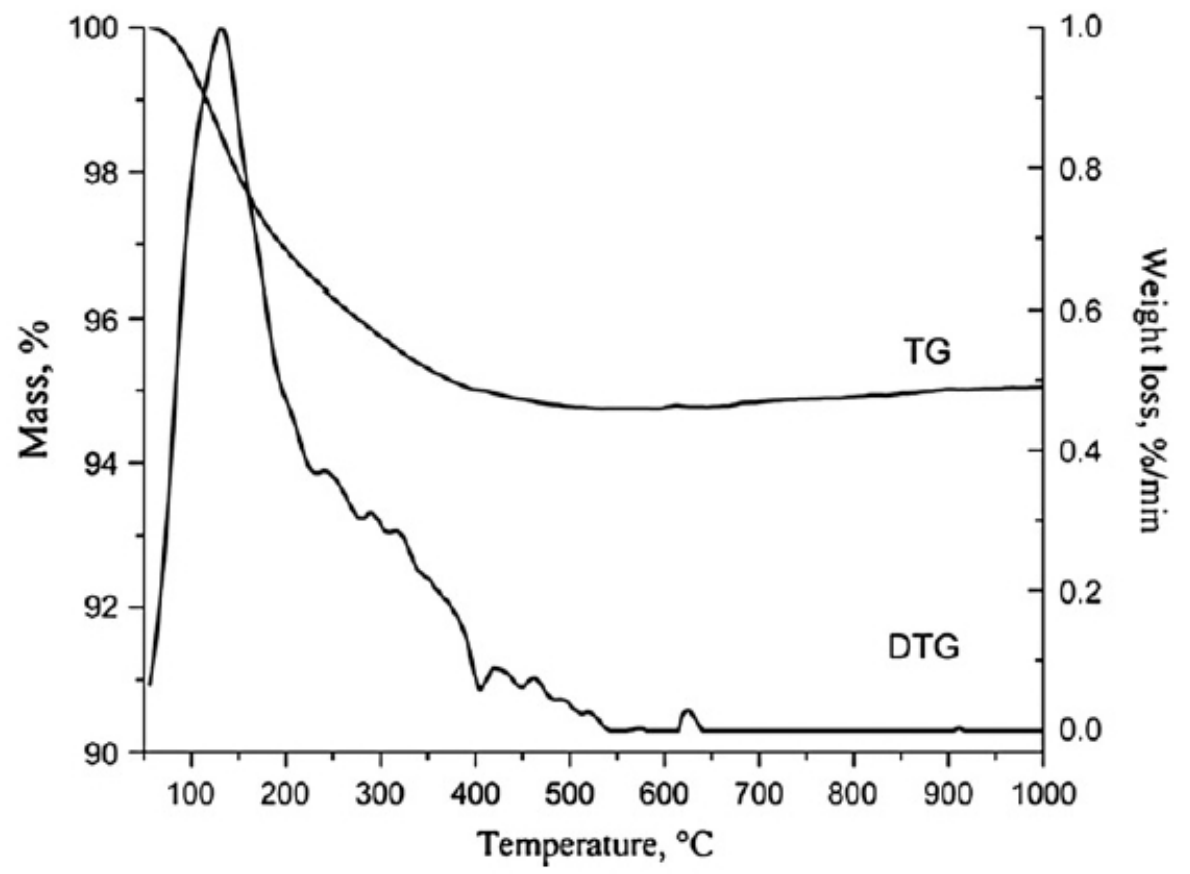

Fig. 1. TG/DTG curves of the KAS sample after of thermal plasma processing. The heating rate was $10^{\circ} \mathrm{C} / \mathrm{min}$. 


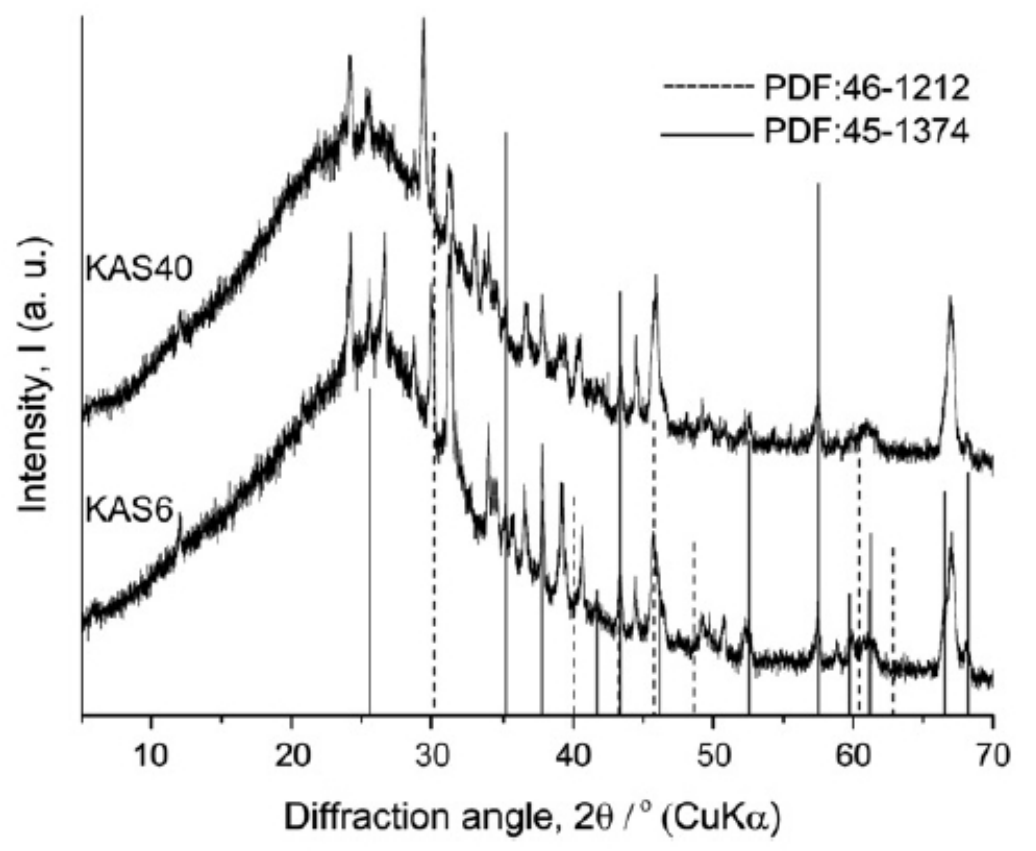

Fig. 2. XRD pattern of the KAS powder after rf thermal plasma processing.

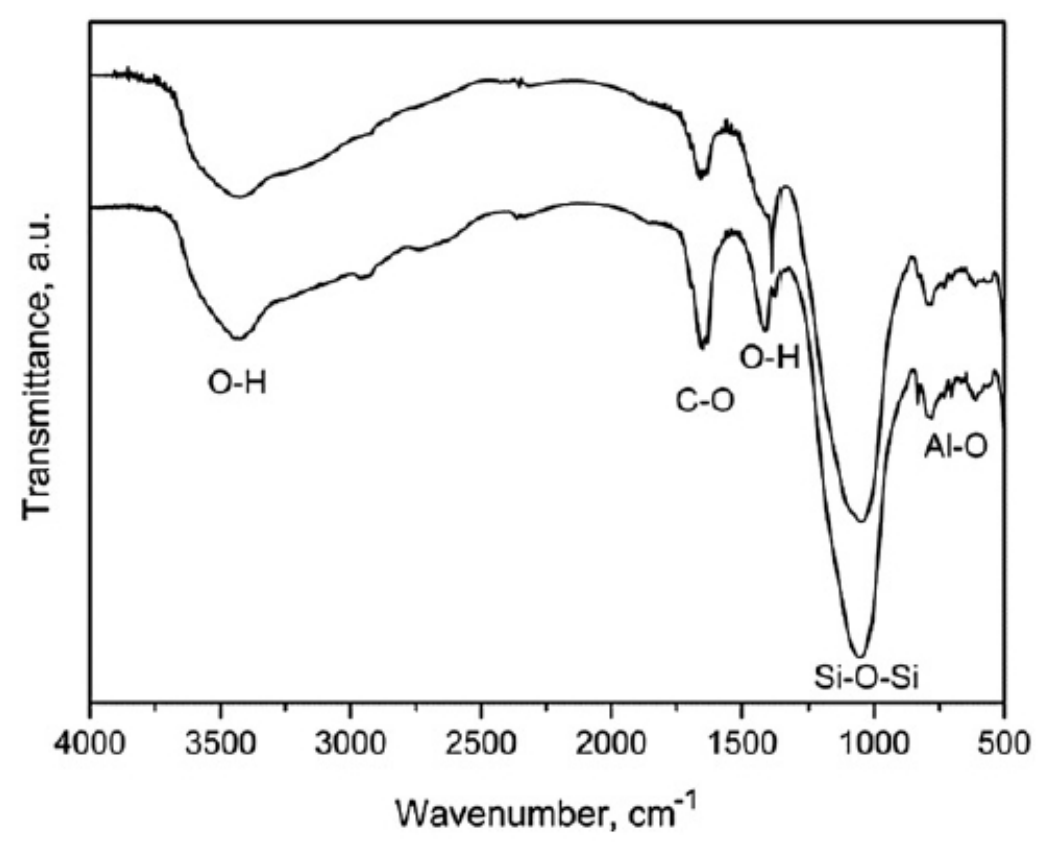

Fig. 3. FT-IR spectra of the KAS40 and KAS6 samples after fr thermal plasma reaction. 

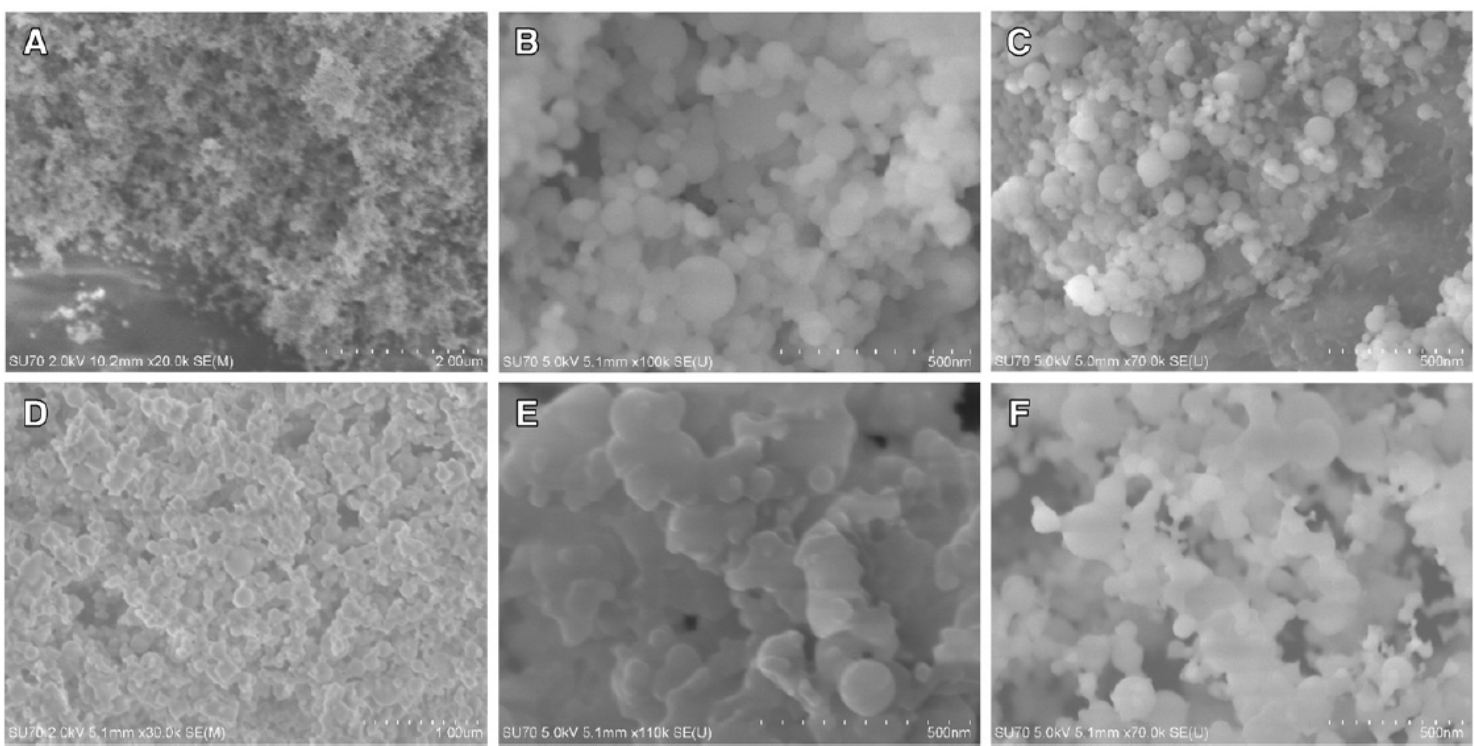

Fig. 4. SEM images of the KAS40 powders at magnifications $20,000 \times(A), 100,000 \times(B)$, $70,000 \times(\mathrm{C})$ and of the KAS40 powder at magnifications $30,000 \times(\mathrm{D}), 110,000 \times(\mathrm{E})$ and $70,000 \times(\mathrm{F})$.
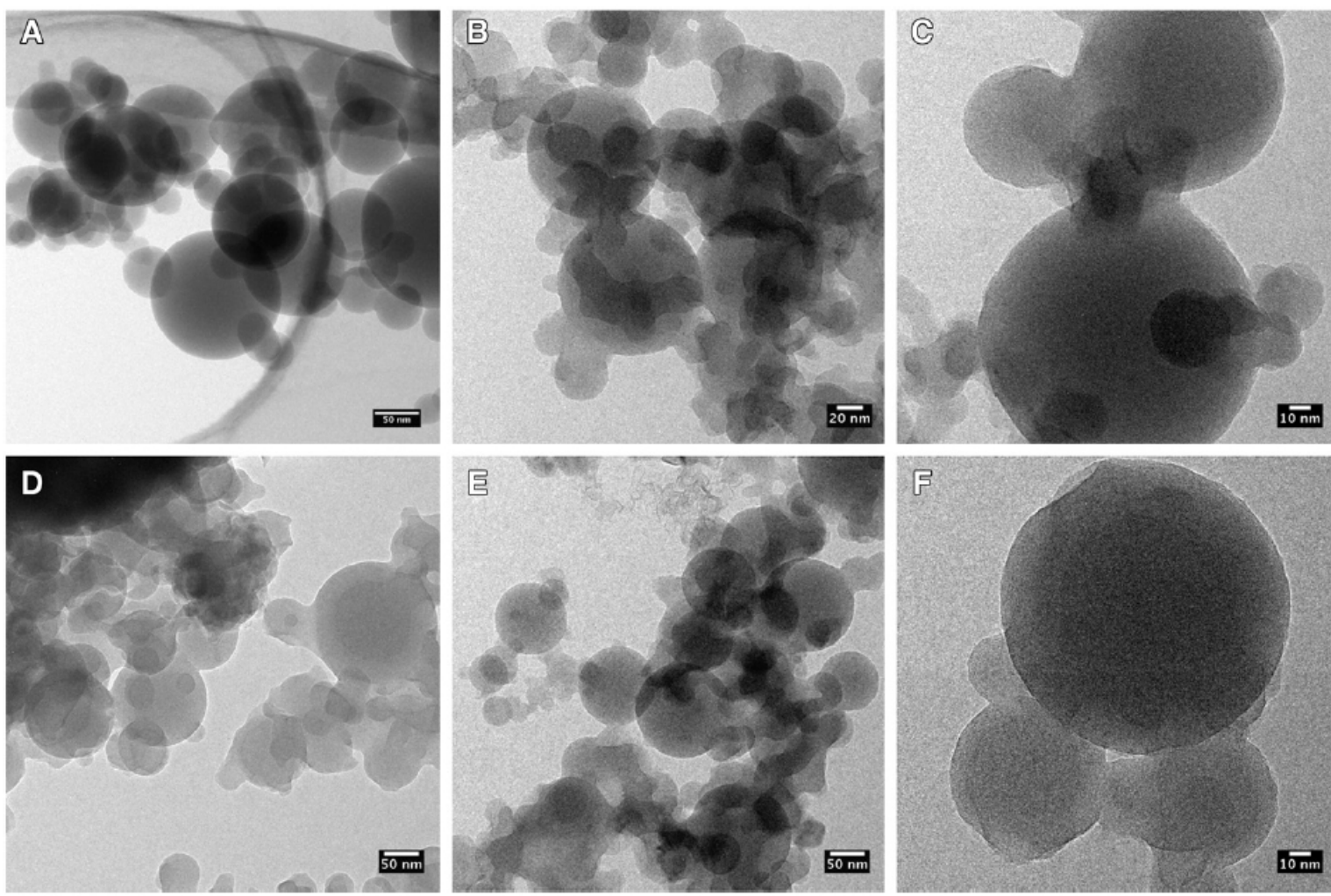

Fig. 5. TEM images of the KAS40 (A, B, C) and the KAS6 (D, E, F) particles taken at different magnifications. 

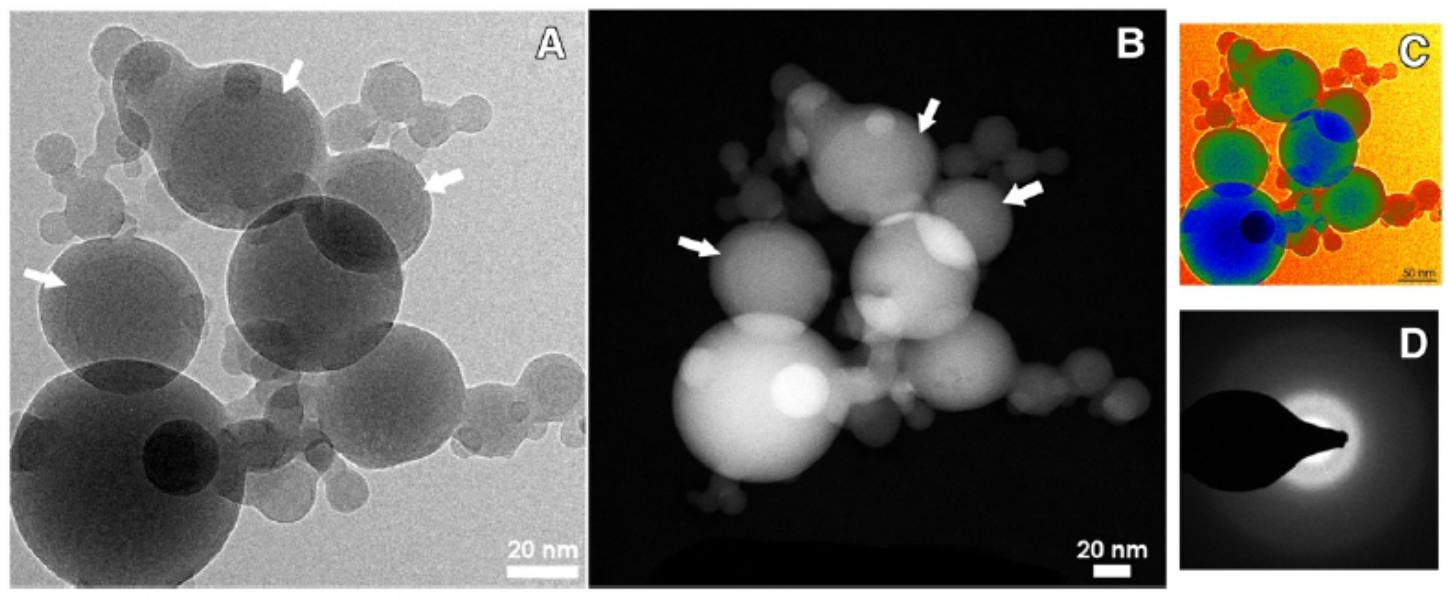

Fig. 6. Images taken from the same agglomerate of particles of the KAS40 sample, using different types of contrast formation in (S)TEM (A) BF-TEM image, (B) HAADF-STEM image. Arrows indicate particles with a sharp change in contrast, which can be attributed to the core/shell structure formation. Temperature colour representation from BF-TEM helping to visualise sharp change in mass-thickness contrast (C). Diffraction pattern (D) clearly showing that the particles are amorphous.

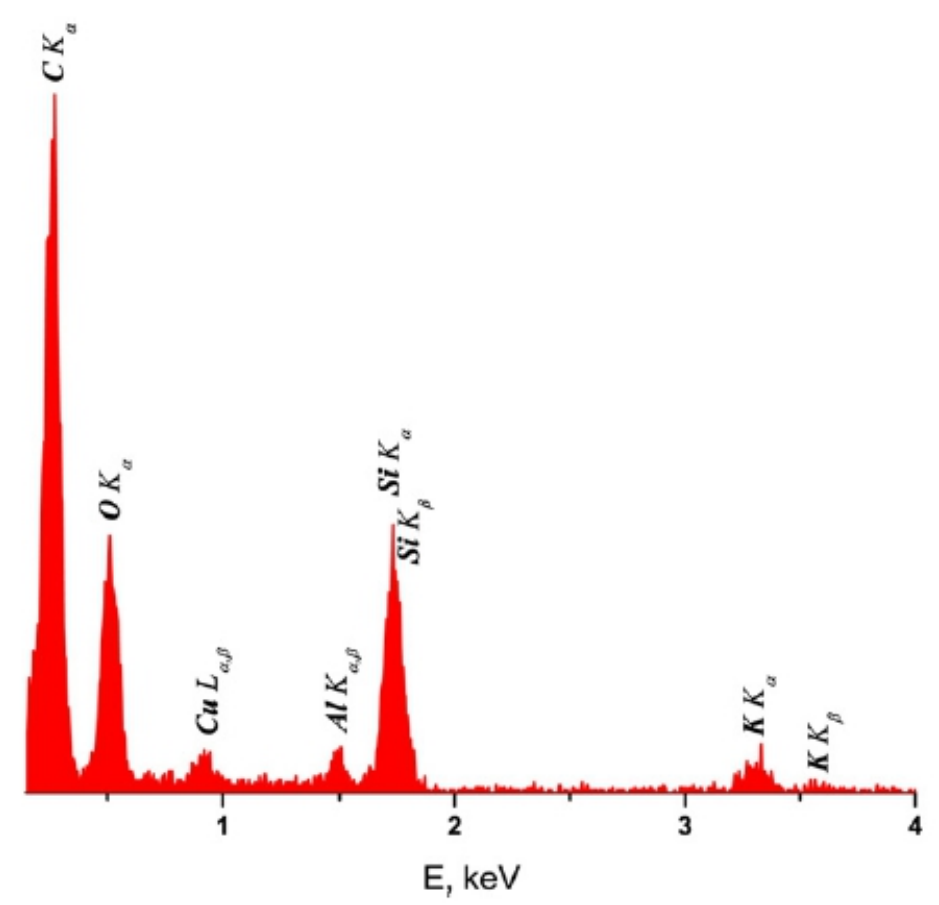

Fig. 7. EDAX spectra of the KAS40 sample. The $\mathrm{Cu}$ and $\mathrm{C}$ signals come from the holey carbon film and the supporting grid. 

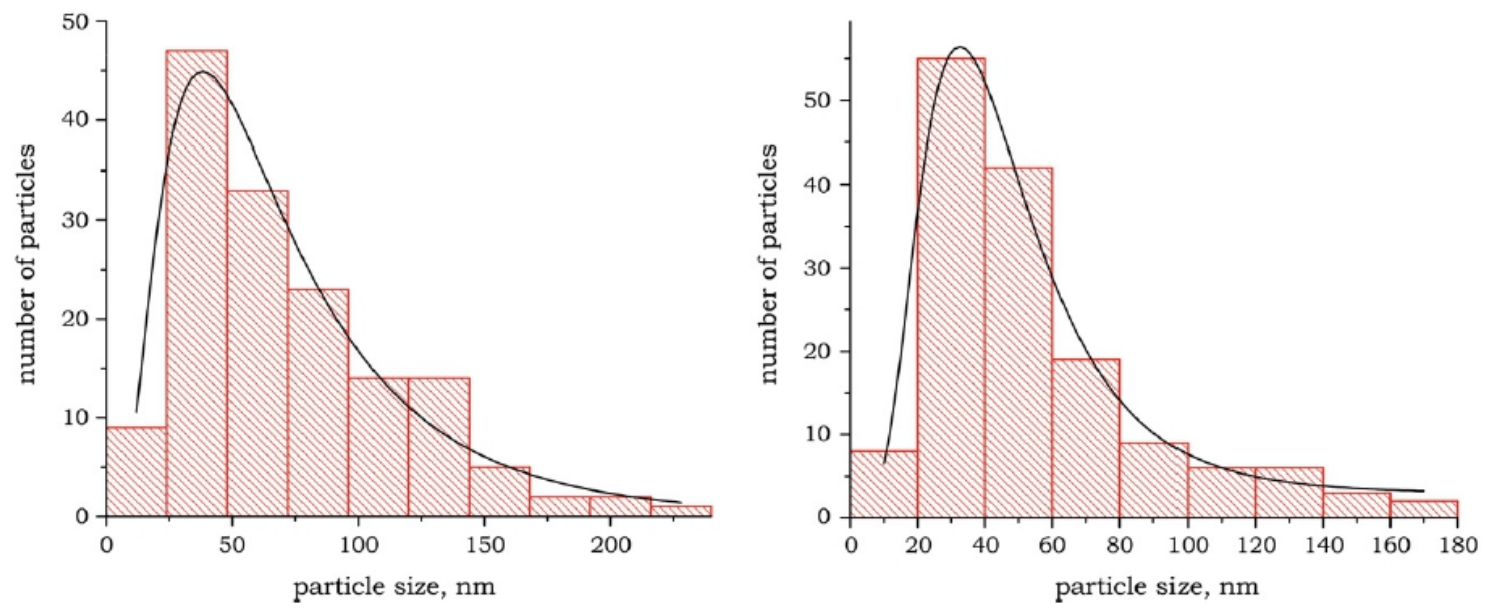

Fig. 8. Particle size distribution for the KAS6 (at left) and KAS40 (at right) samples. 